\title{
Vibration tests of wall segments
}

\author{
Mariusz Żółtowski ${ }^{1, *}$ \\ ${ }^{1}$ UTP University of Science and Technology, Management Department, 85-790 Fordońska 430, \\ Bydgoszcz, Poland
}

\begin{abstract}
In this study author described the degradation testing methodology with use of vibration on building structures to assess measures propagation of vibration energy in the masonry segments. Theoretical analysis and practical verification of susceptibility testing information of the proposed measures vibration processes indicate broad possibilities for their use. Recognizing the need to improve methods of testing machines and structures in order to assess their state of degradation - in this work author shows the important results in the field of effectiveness verification of proposed measures of masonry segments.
\end{abstract}

\section{Introduction}

Aging and consumption are inextricably linked with the existence of buildings, affecting destructive to their technical condition and leading inevitably to the possibility of observing their damage state. The combined impact of these degradation structure forms of the object leads to the development lesions, leading to the interruption of the structure correct functioning, and even the loss of physical cohesion of object.

The degradation of building materials and structures, can be track by finding changes in their degradation, and allows to predict damage, which determines the effectiveness of nondestructive testing and technical diagnostics.

Machines and structures requires to bring them (and discharge) respective types of energy, as well as a variety of material-technical products depending on the type of structure. Therefore it is needed to take into account the potential handler, which is used to rehabilitate the potential utility consumed during the existence of the building construction. Values parameters change characterize presented potentials, depends primarily on:

- the type of tasks performed by the structures,

- external conditions of existence (functioning) the construction,

- technical state of constructions (buildings)

- qualifications of the users and employees performing a repair works. ${ }^{*}$

The utility potential of the building structure can be defined as a material resource and energy to ensure its ability to use. This potential decreases during the existence of the structure while increasing its potential handler. Operating potential is interpreted as a material and energy resource needed to renew the potential utility of construction (buildings). These two types of potentials form an exploitation potential, which

\footnotetext{
*Corresponding author: mazolto@utp.edu.p1
} 
characterizes the building structure as its ability to be used in accordance with the needs for which it has been enabled.

Against the background of the existing rules of previous studies in this paper author proposed research methodology, which represents a new approach in the study of building materials destruction. It uses a newer experimental research in the evaluation of changes in the degradation of the buildings structures, which is based on dispersed vibration energy and modal analysis methods which describes the degradation state of the tested object.

Dedicated algorithms methodology of degradation vibration testing in the construction industry is offend cooled the dynamic properties test procedure of the various components, machines and structures, including modeling, simulation studies and their verification in the research bench and supplies. It requires the association structure traits of evaluated object, with a set of measurement and evaluation processes of output. Dedicated algorithm for research of vibration energy analysis in the study of machines and structures construction products includes:

- formulate a research problem;

- acquisition and processing of vibration energy measurement;

- optimization the quality of vibration symptoms;

- models of degradation state binding measures;

- inference.

In general testing methodology of degradation contains detailed procedures of the study: the data acquisition system, processing and statistical inference.

The major issue of this work is to verify the effectiveness of the proposed above degradation testing methodology in the application of vibration energy propagation measures.

\section{Masonry constructions research}

The most reliable method for determining the wall resistance in the existing structure is to examine the strength of the samples taken from the wall out of its structure. However these wall elements can have relatively large dimensions and therefore is downloadable from the existing wall structure sample of this size is rarely possible. In the case of non-perforated wall masonry (full brick, cellular concrete blocks) can be cut into cylindrical samples, like in the case of concrete structures [1,4]. Research masonry drilling can be conducted in different ways, which has an impact on the results. Correction factors samples (normalized strength of the wall) should be characterized by the trial elements.

The safety factors values of the wall are determined according to the category of production control and the category of the works on site. A distinction is made:

- category A of works - when work is performed by trained team under the supervision of master mason and apply grout produced in the factory. If the mortar are made on site, controlled dosing of ingredients and mortar strength and quality are controlled by a qualified person $[2,3]$.

- B categories of works - when the conditions of category A are not met, and the work quality monitor is performed by an authorized person, authorized by the contractor.

The decision to adopt the performance category is made by the designer according to the contractor confirmation by observations at the site. For exceptional design situations, regardless of the masonry production category and performance category, you can take: for wall $-\gamma_{m}=1.3$; for anchoring of reinforcing steel $-\gamma_{m}=1.15$; for reinforcing steel $-\gamma_{m}=1.0$.

The basic information for the existing structure analysis is the knowledge of the wall elasticity modulus. The relationship between stress and strain is characterized by strain limits $\varepsilon_{L}$ and $\varepsilon_{u}$, which is recommended to take according to the test results. Currently, there are technical possibilities of drilling in the walls of a diameter about $150 \mathrm{~mm}$. Samples 
drilling can be carried out in a vertical or horizontal to the vertical plane of the wall. Based on the research it can be assumed that the relationship between the strength determined on samples cut from the wall, and his strength characteristic compressive strength for horizontal and vertical is about: $f_{k \text {, mean }}=(0.75 / 0.83) f_{k \text {, mean }} \cdot m$, where $f_{k \text {, mean }}$ - standard compressive strength obtained from the wells, $m<1$ - coefficient taken depending upon the masonry.

In many countries in order to evaluate the safety of existing masonry wall undertakes research on compression using pressure pads (flat jacks), placed in the horizontal joints of the wall. The different method over the classical evaluation of structural is that of interest is not the strength of the wall, and to securely transfer through the certain strength wall of the expected structure load.

Research of wall compression using pressure pads (flat-jacks), placed in the horizontal joints of the wall (Fig.1).

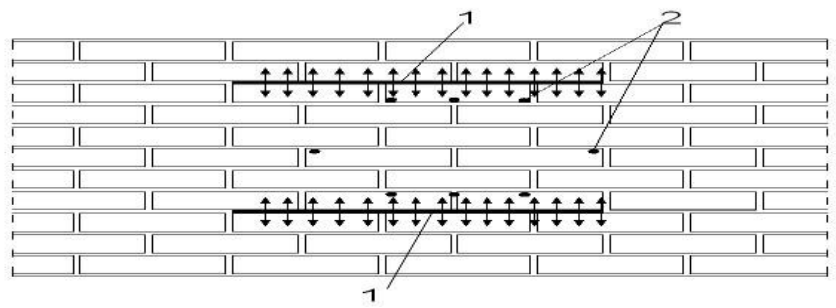

Fig. 1. The essence of the "flat-jacks" method.

Used in the pressure examination pad has a rectangular shape with aspect ratio of $1: 2$ or rounded to better fit the circular saw evacuated space in the joint. The pillows are made of stainless steel having a thickness of 0.8 to $1.0 \mathrm{~mm}$ and a thickness of about $10 \mathrm{~mm}$. The surface area of cushion is about $80000 \mathrm{~mm}^{2}$. Horizontal welds, which have been introduced cushion pressure rupture of the mortar using a circular saw to a depth of not less than $2 / 3$ of the wall thickness. The joints should be away from each other between 430 to $500 \mathrm{~mm}$, which corresponds approximately to the length cushion. On the surface of the wall they are separated by a seam which is arranged by pressure cushions, glued suppositories for measuring (by means of a strain gauge socket) deformation of the wall under the effect of stress $\sigma_{p}$ caused by the pressure pad. Both of the pressure pad are supplied by a single pump. Stress $\sigma_{p}$ induced in the wall is determined by the formula: $\sigma_{p}=K_{m} K_{P}$, where $K_{m}$ constant value taking into account the characteristics of the pads and the rigidity of the welded joint metal pads on the perimeter (This value is determined by scaling the pad in press testing), $K_{a}$ - ratio of the hollow joints (after mortar removal) into the bag, $p$ - the pressure in the cushion caused by the supply pump.

Measurements are usually stress in the wall corresponding to the maximum load test piece construction in the foreseeable conditions of use of the object, or a little more. As a rule, it is a tension not exceeding 0.5 the estimated strength of the wall. Tests may also lead to stress short of strength, but it is not always necessary in view of the purpose of the investigation and with greater efforts of the - longer receive scratches on the wall.

The most reliable method, however, is not always possible to apply, to remove the item from the test masonry structures and to determine the value of $f_{B}$ in accordance with the requirements of the standard. In the case of non-perforated masonry rather than remove the entire element can download into cylindrical sample of material from which the elements were walling and on that basis determine the strength $f_{B}$ of masonry element. The diameter of the sample is typically 50 to $60 \mathrm{~mm}$, and a correction factor of the sample converts the strength of the strength of the brick $f_{B} 0.90[1,4]$. Error in assessing the value of $f_{B}$ $\pm 10 \div 15 \%$. The strength of the bricks you can explore by the Schmidt hammer $[1,3]$. 
Compressive strength of mortar sets of rules "by feel", scraping it with a sharp instrument, or using research mortar adhesion to masonry - Using the "pull-off" (Fig. 2).
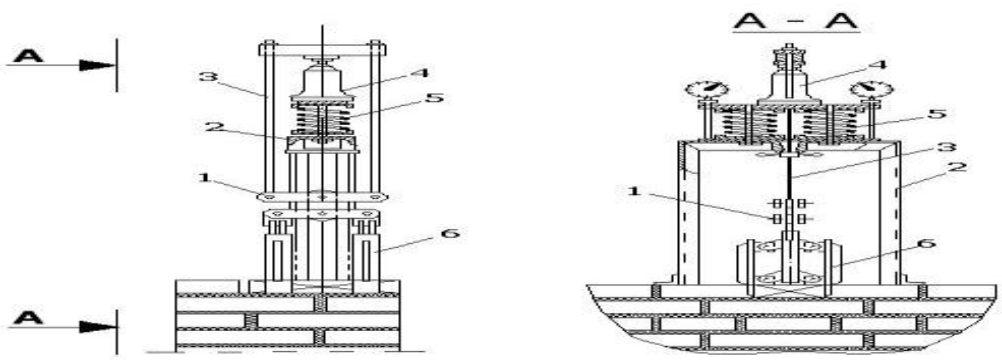

Fig. 2. Mortar adhesion research.

A different test method can safely transfers through the wall and a specific strength of the expected load of the structure is to subject the wall compression with flat pressure pads (flat jacks), placed in the horizontal joints of the wall, emptied the previously mortar Fig. $3[1,4]$. The presented methodology can be used also when the masonry compressive strength is known (e.g. the retrieved drilling of masonry) and the mortar strength (e.g. on the basis of a mason hammer sample), and - a necessary condition - the coefficient of variation $v_{x}$ (e.g. ultrasonic method). The wall strength characteristic $f_{k}$ can be determined using data from the PN-B-03002: 1999 constitute a generalization of the collected test results. Testing the strength of the wall shear along joints method - "In situ".
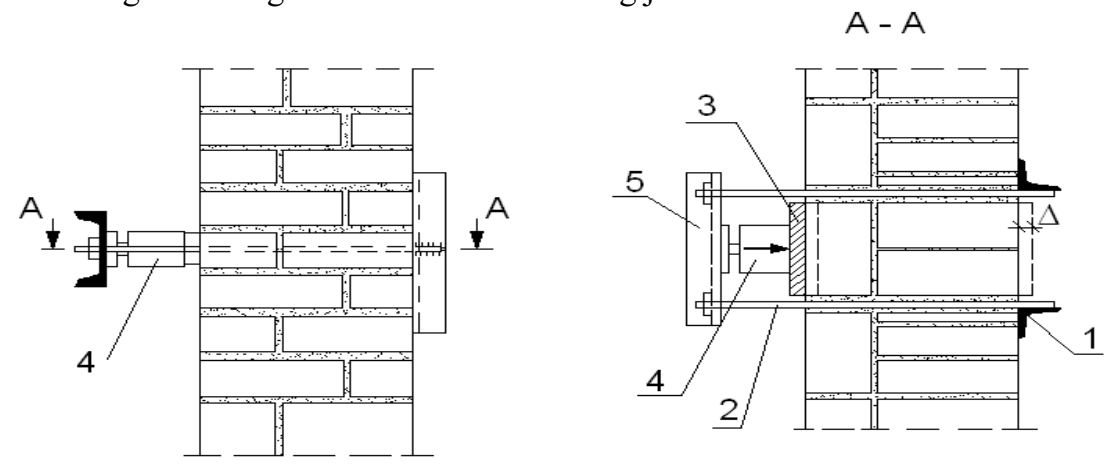

Fig. 3. The idea of the method of "in-situ"

When there is no data on homogeneity testing of the wall, it is usually identified with uniformity endurance masonry, as determined usually by the sclerometric testing $[1,3,4]$.

\section{Masonry segments research}

Dynamic properties of building structures have a direct impact on the level of generated vibrations emitted noise, fatigue strength, controllability and stability of the structure. The analysis of the dynamic properties of the structure is identified based on structural models built on the basis of experiments or the real object.

Assessment of dynamic building structures using processes vibration requires the association structure traits evaluated object with a set of measurement and evaluation processes output. Introduced vibrations to the object are dynamic and keep the conditions of equilibrium between the state of inertia, elasticity, damping and extortion. Disturbances propagating from the source as a wave in a manner dependent on the physical properties 
and the limits of the configuration, dimensions and shapes of buildings. This results, consequently, the power dissipation of the waves, the diffraction, reflection, and the overlap. As a result, the existence of the input and execution states representing the transition characteristics and properties of the structure is formed that can be measured by a number of symptoms characteristic of the processes included in the output $[2,5,6,12,14]$.

For verification tests author selected wall segments made of ceramic elements, which for the purposes of this study were determined depending on the manner of their execution, as in Table 1. They were also given the destructive force the segment walled specified on the testing machine, available in a research laboratory.

Table 1. Characteristic of studied masonry segments.

\begin{tabular}{|c|c|c|c|c|}
\hline Material & $\begin{array}{c}\text { sample } \\
{[\mathrm{cm}]}\end{array}$ & reinforcement & $\begin{array}{c}\text { sample } \\
\text { sign }\end{array}$ & $\begin{array}{c}\text { destructive } \\
\text { force } \\
{[\mathrm{kN}]}\end{array}$ \\
\hline \multirow{3}{*}{ ceramic brick } & \multirow{2}{*}{$12 \times 25$} & without & $\mathrm{C} 1$ & 290 \\
\cline { 3 - 5 } & & steel mesh & $\mathrm{CD} 1$ & 295 \\
\cline { 3 - 5 } & Ruredil's mesh & CR1 & 185 \\
\hline
\end{tabular}

Tested wall segment of ceramic bricks was made without reinforcement, with reinforcement steel mesh and reinforced Ruredil's mesh [9].

In the traditional research the strength subjected to a compression test to determine the limit of the destruction of the segment. In this study we determined waveform distortion depending on the load and the maximum value of the load, to destroy segment. Samples were subjected to an alternating load from $0 \mathrm{kN}$ and the breaking force (breaking force values for individual segments of masonry are given in Table.1). Runs destruction from scratch and by buckling up to the destruction observed in the graphs $\sigma-\varepsilon$ (Fig. 4). Courses of load changes, $(\mathrm{kN})$ from 0 to the destruction force helped to predict the load points for each segment, for which further research has been carried out the destruction of the state of vibration.
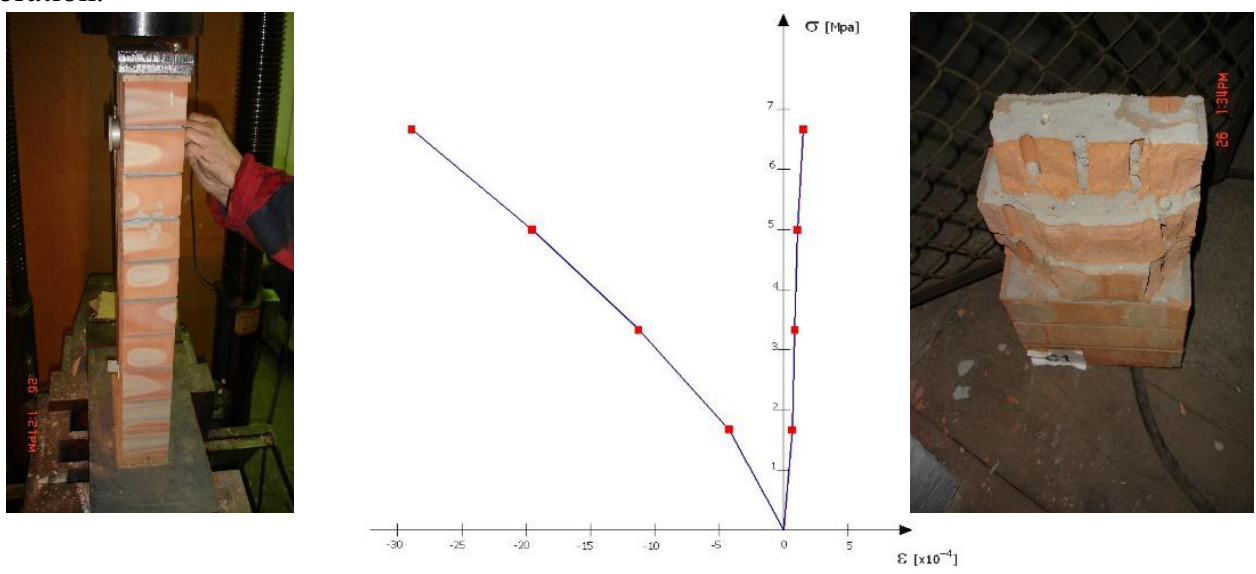

Fig. 4. Determination of breaking force and deformation $\sigma-\varepsilon$ for sample $\mathrm{C} 1$.

Determined elasticity segment determines the ability of a material to return to its original form after removal of the external force that has caused deformation of the material. The elastic property of the material has a modulus of elasticity $E$ is calculated by the following formula: 


$$
E=\frac{\sigma}{\varepsilon} \quad[\mathrm{MPa}]
$$

where: $\sigma$ - the tension arising from (or tension) compression force $F_{n}[\mathrm{kN}]$ sample section $A\left[\mathrm{~cm}^{2}\right]$, appointed in [MPa], $\varepsilon$ - elastic deformation caused by stress $\sigma$ calculated from the relative change in length $\Delta L$ to its original length $l$ (elongation caused by the stress) unscaled [-], however:

$$
\sigma \varepsilon=E=F_{n} / A \quad[\mathrm{MPa}] ; \text { and: } \varepsilon=(\Delta l / l) \cdot 100 \%[\%]
$$

including: $F_{n}$ - squeezing force (tensile), $[\mathrm{kN}], \Delta l$ - Change of length [cm]

$A$ - cross-sectional area of the sample $\left[\mathrm{cm}^{2]}, l\right.$ - lengths original $[\mathrm{cm}]$.

The results of the study for all segments of brick are shown in Table 2 and Fig. 4.

Table 2. The results of sample $\mathrm{C} 1$ study.

\begin{tabular}{|c|c|c|c|c|c|}
\hline \multicolumn{6}{|c|}{ C1 sample } \\
\hline \multirow{2}{*}{$\begin{array}{c}\text { load } \\
{[\mathrm{kN}]}\end{array}$} & \multicolumn{2}{|c|}{ reading $[\mathrm{mm}]$} & tension & \multicolumn{2}{c|}{$\mathrm{s}\left[\times 10^{-4}\right]$} \\
\cline { 2 - 3 } \cline { 5 - 6 }$\left[\begin{array}{c}{[\mathrm{MPa}]} \\
\right.$\cline { 6 - 6 }\end{array} & compression & extension & compression & extension \\
\hline 0 & 5.22 & 5.51 & 0.00 & 0.00 & 0.00 \\
\hline 50 & 5.42 & 5.48 & 1.67 & -4.28 & 0.64 \\
\hline 100 & 5.75 & 5.47 & 3.33 & -11.28 & 0.85 \\
\hline 150 & 6.14 & 5.48 & 5.00 & -19.57 & 1.08 \\
\hline 200 & 6.58 & 5.44 & 6.67 & -28.94 & 1.49 \\
\hline 250 & \multicolumn{2}{|c|}{ sample destruction } & 9.67 & & \\
\hline
\end{tabular}

In time of research also wall segments deformation was measured, which is shown in graph $\sigma(\varepsilon)$ to the appearance of cracks in the wall - a sign of the significant effort of the wall and usually causes interruption of research.

The traditional method of masonry structures testing is not always possible, and is often cumbersome to implement. The search for non-invasive way of testing the masonry leads directly to diagnostic testing vibration and modal methods proposed widely for many studies $[4,5,6,9]$. The study segments of masonry was carried out in accordance with the proposed in many studies dedicated to the author's research methodology vibration in building structures, in accordance with the methodology shown in Fig. 5.

\section{MODAL TEST}

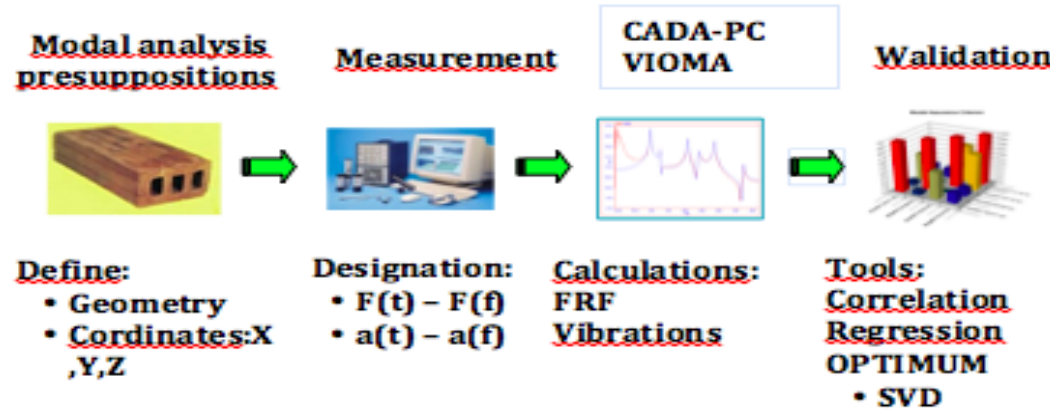

Fig. 5. Vibration research methodology of masonry segments [9].

The identification tests experiment was performed using a specialized signal analyzer, computer as control unit and a calculation interface equipped with special measuring 
software. Each segment tested was putted under the assumed load to extort vibration by modal hammer, and measure hardware recorded both signals the force putted from hammer and the answer at the extortion of the segment.

The basic method of signal processing used in the experiment identification is the frequency analysis, which is carried out either by specialized analyzer, with use of specialized software implemented on the computer used to operate the experiment. Software that was used during the measurements is called LMS TestXpress [9].

The results of the research presents a stresses forces for distinguished states of segments load (Table 2), which provides the basis for further research, and the effectiveness of the developed vibration assessment procedure for masonry segments.

The following Fig. 6, 7, 8 shows the results of such treatment, presenting successively passes force, and the response, also the force amplitude of the vibration acceleration, vibration spectrum of the signal waveform FRF (real and imaginary parts), the transmittance waveforms (parts by real and imaginary), as well as the course of the coherence function.

The study was conducted for prepared 6 different masonry segments, with the extortion in two directions: along the $\mathrm{x}$-axis and $\mathrm{y}$. Presented results below are only some of these tests for a sample segment, along one axis.
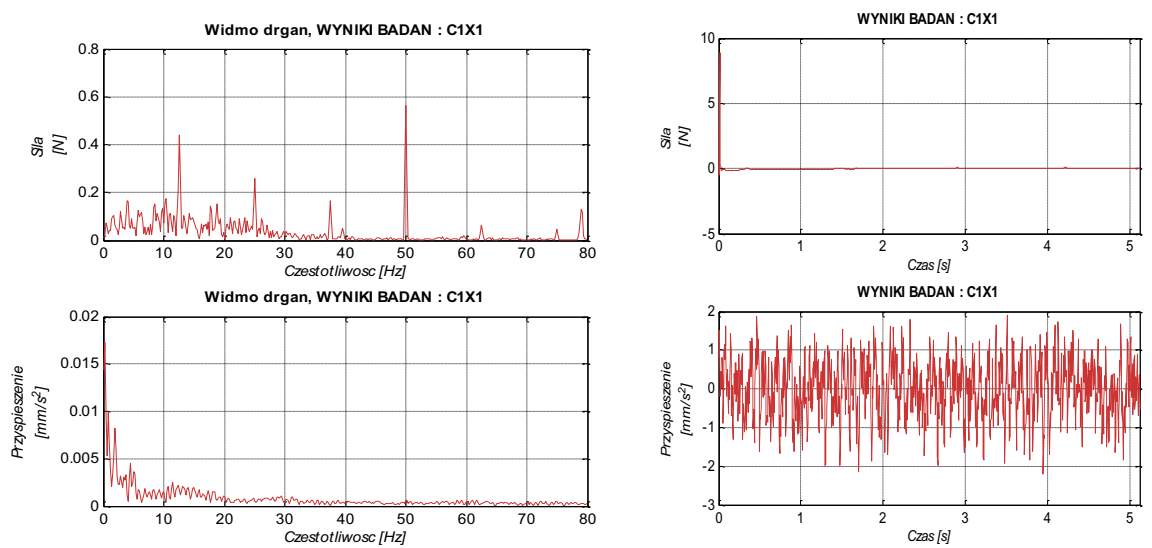

Fig. 6. Strength force and vibration acceleration as a response in the frequency and time domains.
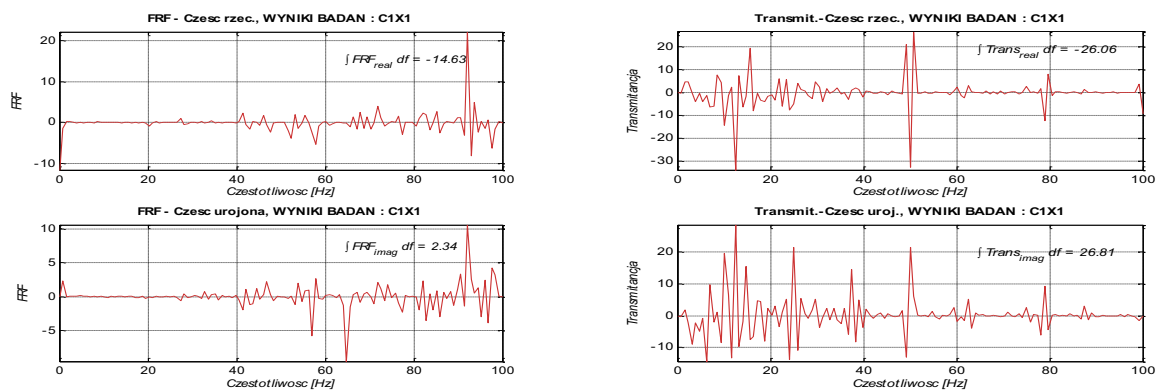

Fig. 7. Examples of waveforms transfer function and FRF (Frequency Response Function). 


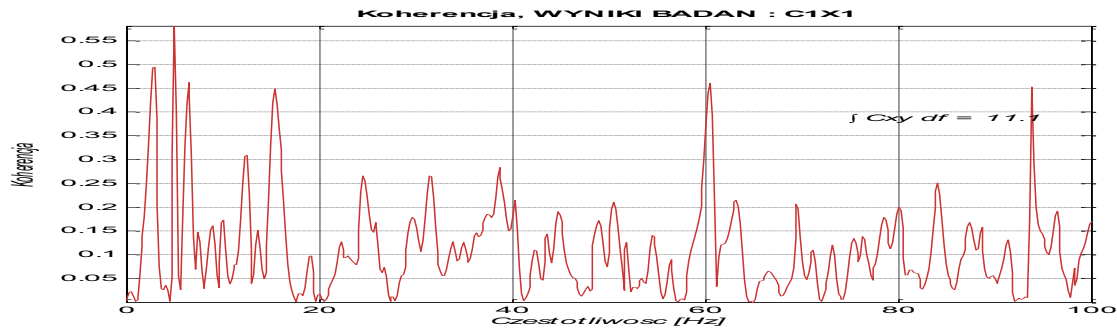

Fig. 8. The results of the coherence function for the segment $\mathrm{C} 1$.

Verification tests developed methods for the evaluation of destruction segments masonry was continued for three segments of masonry load taken from these studies: $0 \mathrm{kN}$, limit the force of destruction segment and the value of the average power load. Specific values of the force loads adopted for the study of individual segments of the masonry is included in Table 3.

Table 3. The figures measure the vibration signal for different load segments masonry.

\begin{tabular}{|c|c|c|c|c|c|c|c|c|c|c|c|c|}
\hline \multicolumn{7}{|c|}{$X$ data } & \multicolumn{6}{|c|}{$Y$ data } \\
\hline \multirow{4}{*}{ C1 } & $\mathrm{kN}$ & $F R F_{r}$ & $F R F_{u}$ & $H(f)_{r}$ & $H(f)_{u}$ & coher & $\mathrm{kN}$ & $F R F_{r}$ & $F R F_{u}$ & $H(f)_{r}$ & $H(f)_{u}$ & coher \\
\hline & 0 & -14.63 & 2.34 & -26.01 & -26.80 & 11.11 & 0 & 15.47 & 5.27 & -16.6 & 9.78 & 15.46 \\
\hline & 150 & 6.67 & 12.06 & -11.56 & -58.72 & 14.97 & 150 & -5.04 & 19.73 & -11.08 & 50.94 & 10.59 \\
\hline & 270 & 12.31 & -6.18 & \begin{tabular}{|l|}
39.83 \\
\end{tabular} & 13.16 & 12.67 & 270 & -24.71 & -9.81 & -31.52 & 26.81 & 18.75 \\
\hline \multirow{3}{*}{ CD1 } & 0 & -21.61 & 2.01 & 43.87 & 12.72 & 15.83 & 0 & 28.64 & 4.17 & -8.57 & -24.88 & 12.37 \\
\hline & 125 & 5.91 & 11.82 & 2.93 & 29.96 & 13.32 & 125 & 4.88 & 21.12 & 29.76 & 33.26 & 11.52 \\
\hline & 295 & 40.93 & -25.89 & -14.28 & 77.32 & 14.76 & 295 & 4.87 & 6.52 & -65.74 & 76.95 & 17.41 \\
\hline \multirow{3}{*}{ CR1 } & 0 & -1.23 & 7.45 & 13.02 & 32.04 & 14.83 & 0 & -22.99 & 8.75 & -16.62 & -59.12 & 15.11 \\
\hline & 150 & -13.79 & 5.81 & 23.66 & 23.77 & 12.66 & 150 & 5.94 & 36.81 & 10.89 & 11.12 & 16.67 \\
\hline & 305 & -11.74 & \begin{tabular}{|l|}
-3.72 \\
\end{tabular} & $\begin{array}{l}-5.17 \\
\end{array}$ & 55.73 & 17.56 & 305 & 15.34 & 12.37 & 14.23 & 17.78 & 17.32 \\
\hline
\end{tabular}

The test results of selected vibration estimators shown in Fig. 6, 7, 8 allows quality assessment, but do not allow convenient quantitative inferences about the change of destruction and impact load to a test segment destruction of masonry. All waveforms function has been further developed so (discretized) numerically and used during the inference quality using statistical methods proposed earlier [9]. Depending on measurement of vibration of the load conditions for the various segments of masonry are included in the regression models developed further.

\section{Study of case-effect}

Determining the relationship between measures of the state of destruction and load segments of masonry was carried out using polynomial regression. The table below presents regression models for segments made of ceramic bricks (with the beam cause and effect) was determined for individual measures as well as for all measures simultaneously (Fig. 8, 9). Studies carried out indicated estimators segments brick for the construction of binding model are shown in Table 4. 
Table 4. Results for the construction of polynomial regression model.

\begin{tabular}{|l|l|l|l|}
\hline $\begin{array}{l}\text { Parameters } \\
\text { number }\end{array}$ & FRFr & FRFu & Cohere \\
\hline 1 & -14.63 & 2.34 & 11.11 \\
\hline 2 & 6.67 & 12.06 & 14.97 \\
\hline 3 & 12.31 & -6.18 & 12.67 \\
\hline 4 & -21.61 & 2.01 & 15.83 \\
\hline 5 & 5.91 & 11.82 & 13.32 \\
\hline 6 & 40.93 & -25.89 & 14.76 \\
\hline 7 & -1.23 & 7.45 & 14.83 \\
\hline 8 & -13.79 & 5.81 & 12.66 \\
\hline 9 & -11.74 & -3.72 & 17.56 \\
\hline
\end{tabular}

Regresja wielomianowa

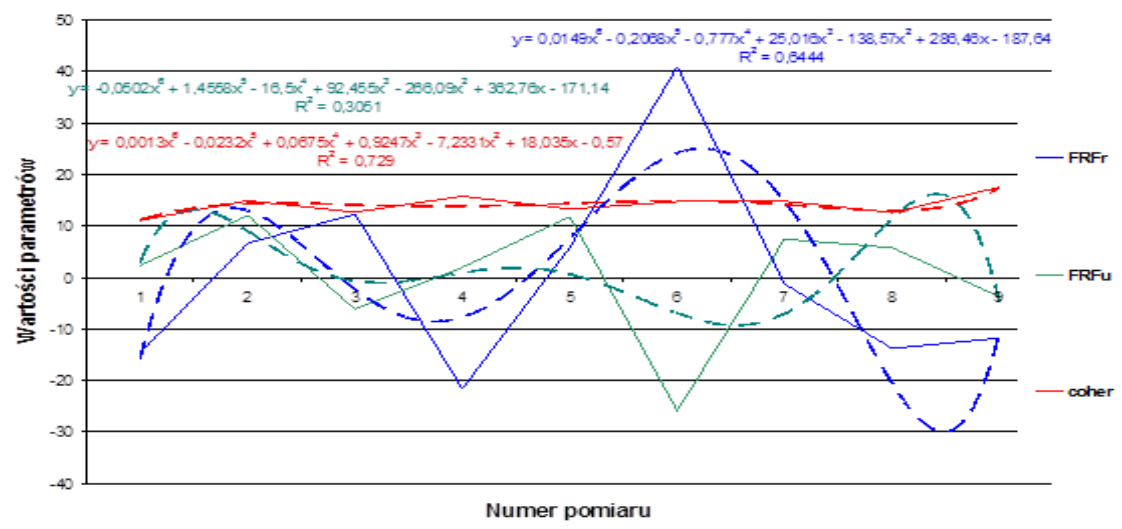

Fig. 8. Masonry segments regression models - axel X.

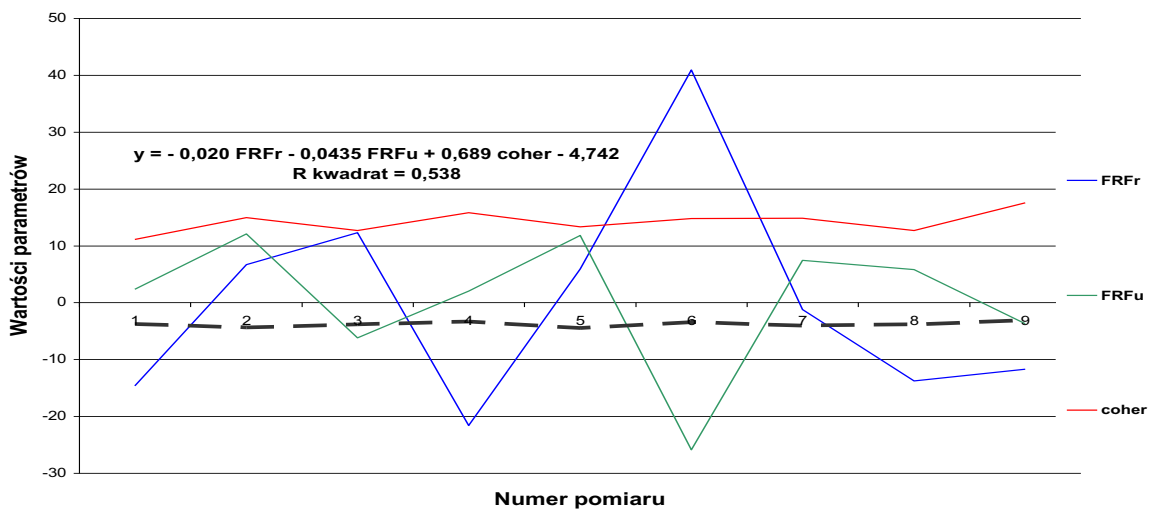

Fig. 9. Mathematic model of masonry segments destruction - axel X.

The drawings for the individual measurements and regression model show the relationships between the destruction of a segment in load values and measured vibration signal. The goodness of the models was assessed using the coefficient of determination $\mathrm{R}^{2}$ assessor, which fitted the trend line to the measurement results.

Carried exemplification of methods on a group of masonry segments determines the model inference in terms of quality degradation of the studied masonry segments, 
and confirms the accuracy and efficiency of the vibration research methodology development for construction industry $[9,13,14]$.

\section{Summary}

These considerations of this study confirm the usefulness of vibration measures and modal model parameters from experimental modal analysis to assess the destruction state of masonry structures. The following figures for individual measures and collective regression models shows the cause relationships - effect relationships between the values of segment destruction and the vibration signal. The goodness of the models was assessed using the coefficient of determination $R^{2}$, evaluating the fit of the trend line to the measurement results. Carried out in this work method exemplification confirmed the compliance and effectiveness of the proposed research methodology to the group of masonry segments as a method for the study of vibration in construction. Positively, therefore, we verified the assumptions developed methodology of research on the elements applied to the masonry segments, which will let author to study this methodology on bigger real objects in the future.

\section{References}

1. T. Chmielewski, Z. Zembaty, Podstawy dynamiki budowli (ARKADY Warszawa, 1998)

2. Z. Janowski, Wymagania konstrukcyjne i wykonawcze murów. (Konstrukcje murowe, 1998)

3. J. Kubica, Własności wytrzymałościowe elementów murowych, zapraw $i$ wykonanych $z$ nich murów (Wytrzymałość muru na ścinanie i rozciąganie,. Konstrukcje murowe, 1998).

4. W. Starosolski, R. Jasiński, A. Piekarczyk, Impact-Echo - nowoczesna aparatura do nieniszczących badań konstrukcji betonowych $i$ murowych. (Konferencja Badań Nieniszczących, Zakopane 1999).

5. T. Uhl: Computer-aided identification of mechanical structure models (Scientific Technical Publishers, 1997)

6. B. Żółtowski, M. Łukasiewicz, Diagnostyka drganiowa maszyn (ITE-PIB Radom, 2012)

7. B. Żółtowski, M. Łukasiewicz, T. Kałaczyński, Techniki informatyczne $w$ badaniach stanu maszyn (WU UTP Bydgoszcz, 2012)

8. B. Żółtowski, M. Żółtowski, Vibration signals in mechanical engineering and construction (ITE-PIB Radom, 2015)

9. M. Żółtowski, Operacyjna analiza modalna $w$ badaniach konstrukcji budowlanych (WU UTP Bydgoszcz, 2012)

10. M. Żółtowski, Informatyczne systemy zarzadzania $w$ inżynierii produkcji (ITE-PIB Radom, 2011)

11. M. Żółtowski, Opis drganiowy konstrukcji budowlanych. Logistyka 6 (2014).

12. M. Żółtowski, Investigations of harbour brick structures by using operational modal analysis. Polish Maritime Research, 21, 1 (2014)

13. M. Żółtowski, R.M. Martinod, Technical Condition Assessment of Masonry Structural Components using Frequency Response Function (FRF). Masonry International Journal of the International Masonry Society 29, 1 (2016)

14. M. Żółtowski, R.M. Martinod, Quality identification methodology applied to wallelements based on modal analysis (Civil Engineering the Athens Institute for Education and Research, 2015) 